\title{
Monocyte-derived Macrophages: An in Vitro System for Studying Hereditary Lysosomal Storage Diseases
}

\author{
SHAUL YATZIV, LOIS B. EPSTEIN, AND CHARLES J. EPSTEIN ${ }^{(43)}$ \\ Departments of Pediatrics and of Biochemistry and Biophysics, and the Cancer Research Institute, University of \\ California, San Francisco, California USA
}

\begin{abstract}
Summary
Mature macrophages obtained by the growth and differentiation of blood monocytes have been used to develop an in vitro system for the study of hereditary human lysosomal storage diseases. Maturation of monocytes into macrophages is rapid, and the maximal activities of the lysosomal hydrolases, $\beta$-galactosidase, $\beta$-glucuronidase, $\alpha$-mannosidase, and $\beta$ - $N$-acetyl glucosaminidase, is reached by the seventh day in culture. The rate of ${ }^{35} \mathrm{SO}_{4}$ incorporation into mucopolysaccharides is also maximal at 7 days. Normal macrophages attain a steady state of ${ }^{35} \mathrm{SO}_{4}$ labeling within $5 \mathrm{hr}$ of culture and degrade about $60 \%$ of sulfated mucopolysaccharides in $\mathbf{5}$ hr. By contrast, macrophages from patients with the Hunter syndrome (MPS II), when grown in MPS II serum, degrade only $19 \%$ of sulfated MPS within $12 \mathrm{hr}$ and incorporate more ${ }^{35} \mathrm{SO}_{4}$ into MPS. Significant correction of the metabolic defects is achieved by incubation of the Hunter syndrome macrophages in normal serum, demonstrating that the abnormal MPS II macrophages are responsive to exogenously supplied enzyme ( $\alpha$-L-iduronate sulfatase). Preliminary studies of MPS turnover in macrophages from two obligate MPS heterozygotes are indicative of partially impaired MPS degradation, with increased ${ }^{35} \mathrm{SO}_{4}$ incorporation and a lower rate of ${ }^{35} \mathrm{SO}_{4}$-MPS degradation.
\end{abstract}

\section{Speculation}

The human blood-derived macrophage system should be a useful one for the investigation of enzyme replacement and other modes of therapy for the lysosomal storage diseases.

During the last several years, inherited lysosomal storage disorders have become the focus of interest for clinicians and scientists in biochemical genetics, and intensive research in this field has been the basis for elucidation of the primary biochemical defects in many of these genetically determined diseases $(25,29)$. Cultured skin fibroblasts which contain the relevant lysosomal enzymes have been the preferred cells for study in most of the storage disorders because of their well known advantages of ready availability and easy maintenance in culture for long periods of time. In addition, they are useful models for the cultured amniotic fluid cells used in prenatal diagnosis. However, cultured skin fibroblasts are not representative of the reticuloendothelial cells which are the principal in vivo sites of storage in lysosomal disorders such as Gaucher disease $(5,13)$, Niemann-Pick disease $(5,14)$, and $\mathrm{GM}_{1}$ gangliosidosis $(19,32)$. It is our feeling, therefore, that the use of the macrophage, a reticuloendothelial type of cell, as a tool for study can provide additional information about the biochemical changes that take place in vivo in these disorders. Moreover, even in lysosomal storage disorders in which the stored material is only partially accumulated in the reticuloendothelial system (RES), such as in the mucopolysaccharidoses, it is of importance to study the metabolism of stored undegraded substrates and their related lysosomal enzymes in a type of cell different from the fibroblast. Here again the macrophage is a reasonable candidate, particularly since this cell is considered to be, at least in some respects, more active metabolically than the skin fibroblast. Macrophages have a highly developed capacity for phagocytosis and endocytosis. After the ingestion of large numbers of particles they are capable of interiorizing as much as $50 \%$ of their plasma membrane in the form of phagosomes within 3-4 hr $(7,16)$. They also contain high lysosomal hydrolase activities which are dependent on serum concentration, the nature of the phagocytized substance, and overall pinocytic and phagocytic activities $(1,8)$, factors which may be relevant to the way by which macrophages handle the substances accumulated within their lysosomes.

Still another reason for using macrophages as an experimental system is the interest in attempting to correct the metabolic defects in the lysosomal storage disorders by administration of exogenous enzymes. Given their similarities to the in vivo storage cells, it seems reasonable to consider macrophages as being more suitable than fibroblasts for such studies, particularly with regard to material stored in RES-rich visceral organs.

Much of the information on the properties of macrophages has been derived from studies performed with peritoneal cells obtained from animals $(16,35)$ since relatively large quantities of mononuclear phagocytes can be obtained by simple lavage (8). However, peripheral blood leukocytes can serve as a readily available source of monocytes which will, in turn, differentiate into mature macrophages if cultured for a relatively short period of time. Combined morphologic and biochemical studies $(26,35)$ have provided a great deal of information on the main events and changes which take place during the process of maturation of monocytes into blood-derived macrophages. Such macrophages, from both animals and human sources, have been studied extensively in vitro with regard to their role in immunology, inflammation, and host defense $(17,24,31,36)$. However, the use of mature human peripheral blood monocyte-derived macrophages as a tool for the study of inherited lysosomal storage disorders in vitro has not been explored extensively. The only previous work using a similar system was reported in 1971 (9). In this paper we present data on the metabolism of mucopolysaccharides in bloodderived macrophages of normal individuals and of patients with the Hunter syndrome (MPS II). The partial correction of the metabolic defect by supplementation of the culture medium with fresh normal plasma is also discussed, as is the potential use of the blood-derived macrophage system for the detection of MPS II heterozygotes.

\section{MATERIALS AND METHODS}

\section{CELL CULTURE}

A monocyte-enriched lymphocyte layer was obtained on a Ficoll-Hypaque gradient according to the method described by Böyum (4). After receiving informed consent by the protocol 
approved by the institutional Human Experimentation Committee, heparinized blood was obtained from normal donors and patients, diluted 1:1 with phosphate-buffered saline (PBS), and mixed gently. The diluted blood was carefully layered on FicollHypaque ( 3 vol blood-2 vol Ficoll-Hypaque) and centrifuged (International centrifuge model PR-2) at $500 \times \mathrm{g}$ for $45 \mathrm{~min}$ at $20^{\circ}$. The upper cell band, which contained the mononuclear cells, was resuspended in PBS, centrifuged once at $25 \times g$, and then washed twice in Hanks' medium supplemented with $5 \%$ fetal calf serum to remove platelets. The cells were finally resuspended in McCoy's medium at a concentration of $10^{6}$ monocytes $/ \mathrm{ml}$, and 1 $\mathrm{ml}$ of the suspension was added to small Leighton tubes $(16 \times 85$ $\mathrm{mm}$ ), each of which contained a glass coverslip. Differential counts were obtained from Giemsa-stained cytocentrifuge preparations. The mononuclear cells were incubated in $5 \% \mathrm{CO}_{2}$ at $37^{\circ}$ and washed with McCoy's medium with 30\% human serum at 2 and $5 \mathrm{hr}$ on the first day and on the third, fifth, and seventh day of culture thereafter. The lymphocytes are removed by the frequent washing, and a homogenous population of monocytes is achieved by the first day of culture (11).

\section{ENZYME ACTIVITIES}

To examine the specific activities of lysosomal hydrolases during the process of macrophage maturation, two to four coverslips containing cells at a specific stage of maturation were removed from the Leighton tubes, washed four times in normal saline to remove serum proteins, and then transferred to a disposable siliconized glass tube $(12 \times 7 \mathrm{~mm})$ containing $0.2-0.5 \mathrm{ml}$ normal saline. After initial mechanical fragmentation of the coverslips into very small pieces, the cells were subjected to six cycles of freezing and thawing in the presence of Triton X-100 added to a final concentration of $0.1 \%$ ( $\mathrm{vol} / \mathrm{vol})$. The homogenate was centrifuged at $4^{\circ}$ at $600 \times g$ for $10 \mathrm{~min}$, and the supernatant was used for determinations of protein concentration (22) and lysosomal enzyme activities.

In some experiments, the lysosomal enzymes were extracted in

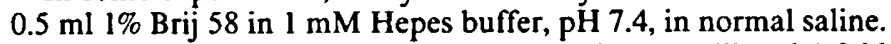
After $10 \mathrm{~min}$ at room temperature, the solution was diluted 4-fold with the Hepes-saline buffer and centrifuged as before (15). For extraction by sonication the fragmented coverslips were suspended in $1 \mathrm{ml}$ normal saline and exposed to two 30 -sec bursts. The suspension was then centrifuged as described before.

The substrates (obtained from Sigma Chemical Company) used for enzyme assays were prepared as follows: for $\beta$-galactosidase, 4 methylumbelliferyl- $\beta$-D-galactopyranoside $(0.5 \mathrm{mM})$ in $0.1 \mathrm{M}$ sodium acetate buffer, $\mathrm{pH} 4.5$; for $\beta$-glucuronidase or $\alpha$-mannosidase, 4 methylumbelliferyl- $\beta$-D-glucuronide $(2 \mathrm{mM})$ or 4 methylumbelliferyl- $\alpha$-D-mannopyranoside $(2 \mathrm{mM})$, respectively, in 0.1 $\mathrm{M}$ sodium acetate buffer, $\mathrm{pH} 4.75$; and for $\beta$ - $N$-acetylglucosaminidase, 4 methylumbelliferyl-2-acetamido-2-deoxy- $\beta$-D-glucopyranoside $(0.5 \mathrm{mM})$ in citrate-phosphate buffer, $\mathrm{pH} 4.6$. The assays were performed by adding $0.4 \mathrm{ml}$ of the appropriate buffersubstrate solution to $10 \times 75 \mathrm{~mm}$ plastic tubes. The tubes were equilibrated at $37^{\circ}$, and $0.1 \mathrm{ml}$ of appropriately diluted enzyme (in a solution of $1 \mathrm{mg} / \mathrm{ml}$ bovine albumin in $0.025 \mathrm{M} \mathrm{NaCl}$ ) was then added and the mixture incubated at $37^{\circ}$ for $1 \mathrm{hr}$. After incubation, $2.0 \mathrm{ml} 0.4 \mathrm{M}$ glycine- $\mathrm{NaOH}$ buffer, $\mathrm{pH} 10.3$, were added to terminate the reaction and to enhance the fluorescence of the liberated 4-methylumbelliferone. A reagent blank was produced by adding $0.1 \mathrm{ml}$ of the diluted enzyme sample to a tube containing $0.4 \mathrm{ml}$ buffer-substrate solution and $2.0 \mathrm{ml}$ glycine$\mathrm{NaOH}$. Fluorescence was measured with a model SPF $125 \mathrm{spec}-$ trophotofluorometer (American Instrument Co., Silver Springs, MD) with excitation and emission wave lengths set at $368 \mathrm{~mm}$ and $448 \mathrm{~nm}$, respectively. Enzyme activity is expressed as nanomoles of 4-methylumbelliferone released per hr per mg protein.

$$
{ }^{35} \mathrm{SO}_{4} \text {-MPS TURNOVER }
$$

Peripheral blood monocyte-derived macrophages cultured in small Leighton tubes were incubated in McCoy's medium in which $\mathrm{MgCl}_{2}$ was substituted for $\mathrm{MgSO}_{4}$. The medium was supplemented with $30 \%$ hun $n$ serum either from normal individuals or from patients with Mrs II. To each Leighton tube, 3-10 $\times 10^{6}$ cpm carrier-free ${ }^{35} \mathrm{SO}_{4}$ (purchased from Amersham/Searle Corporation) per ml medium were added. At $30 \mathrm{~min}, 2 \mathrm{hr}, 5 \mathrm{hr}, 24 \mathrm{hr}$, and $48 \mathrm{hr}$, four coverslips were washed three times in situ with normal saline and removed from the Leighton tube. They were washed three more times in normal saline and then transferred to a conical centrifuge tube containing $2 \mathrm{ml} 80 \%$ cold ethyl alcohol. The cells were then easily scraped off the coverslips with a small rubber policeman and the coverslips were removed from the centrifuge tubes. The MPS were precipitated and free sulfate extracted four times in $2 \mathrm{ml}$ boiling $80 \%$ ethanol (1 min boiling each time) by the procedure of Fratantoni and Neufeld (12). The cell residue, which contained the MPS, was dissolved in $1 \% \mathrm{NaOH}$ at $100^{\circ}$, and $0.1-$ to $0.2-\mathrm{ml}$ aliquots were used for protein and radioactivity determinations.

\section{RESULTS}

\section{LYSOSOMAL HYDROLASE ACTIVITIES}

The culture of cells on small $\left(0.9 \mathrm{~cm}^{2}\right)$ coverslips in Leighton tubes and the extraction of the lysosomal hydrolases from the cells while they were still attached to the coverslips produced maximal yields of enzyme activity. Scraping tended to disrupt part of the cells, and the use of pronase or trypsin, alone or in combination with EDTA in the conventional concentrations, was not sufficient to remove totally the tightly adherent cells.

The effects of other treatments on the lysosomal hydrolase activities of blood derived mononuclear phagocytes were studied, and the results are summarized in Table 1 . Six cycles of freezing and thawing in the presence of $0.1 \%$ Triton $X-100$ produces the highest specific activities; this appears to be a better preparative treatment than sonication or solubilization with Brij. Freeze-thawing in Triton, which was used for all subsequent experiments, appears to have a dual effect: it detaches the cells from the coverslips and at the same time releases the lysosomal enzymes from the cells.

The specific activities of three lysosomal hydrolases in cells grown in McCoy's medium with fetal calf serum and McCoy's medium with human $\mathrm{AB}$ serum are compared in Table 2 . The activities of all three enzymes are higher in cells cultured in $30 \%$ than in $10 \%$ fetal calf serum. However, when equal concentrations of serum are used, significantly higher activities are obtained in cells grown in human $\mathrm{AB}$ serum than in the calf serum.

The specific activities of four lysosomal hydrolases were determined during the process of maturation from monocytes to macrophages, and the results are presented in Figure 1. The maximal specific activities of all four enzymes are reached between the 7 th and 10th day in culture, after which significant decreases are

Table 1. Lysosomal hydrolase activities in human blood-derived mononuclear phagocytes extracted by different methods

\begin{tabular}{lccc}
\hline & \multicolumn{3}{c}{ Activity, nmol/hr/mg protein } \\
\cline { 2 - 4 } & $\begin{array}{l}\text { Freeze-thaw } \\
\text { Enzyme }\end{array}$ & & \\
\hline Triton X- & & \\
\hline -Galactosidase & $800^{1}$ & 600 & 700 \\
& $(500-1110)$ & $(350-850)$ & $(410-970)$ \\
$\beta$-Glucuronidase & 1200 & 850 & 980 \\
& $(950-1800)$ & $(500-980)$ & $(600-1200)$ \\
$\beta$-NAc-Glucosamin- & 6500 & 4100 & 5200 \\
idase & $(4700-7500)$ & $(3000-5700)$ & $(4100-6700)$ \\
\hline
\end{tabular}

${ }^{1}$ Each value represents the mean value of four different experiments. The ranges of values obtained are given in parentheses. The cells were cultured as described in the text for 7 days in McCoy's medium supplemented with $30 \%$ human $\mathrm{AB}$ serum. 
observed. Since proliferation of monocytes does not occur in vitro, the increases in specific activity observed during maturation into macrophages can be taken to represent true increases in the activities of lysosomal enzymes per cell.

When mature mononuclear phagocytes and skin fibroblasts grown under the same conditions were compared, it was found that the mean specific activities of the enzymes are about 2 times higher in human peripheral blood monocyte-derived macrophages than in human fibroblasts (Table 3 ).

KINETICS OF INCORPORATION AND DEGRADATION OF INTRACELLULAR ${ }^{35} \mathrm{SO}_{4}$-MPS IN NORMAL HUMAN PERIPHERAL BLOOD MONOCYTE-DERIVED MACROPHAGES

In preliminary experiments with monocyte-derived macrophages obtained from normal donors it was found that the rate of sulfate incorporation into mucopolysaccharides reaches the high-

Table 2. Comparison of specific activities of lysosomal hydrolases in blood-derived mononuclear phagocytes grown in McCoy's medium supplemented with different sera

\begin{tabular}{cccc}
\hline & \multicolumn{3}{c}{ Activity, nmol/hr/mg protein } \\
\cline { 2 - 4 } Type of serum & $\begin{array}{c}\beta \text {-Galactosid- } \\
\text { ase }\end{array}$ & $\begin{array}{c}\beta \text {-Glucuroni- } \\
\text { dase }\end{array}$ & $\begin{array}{c}\beta \text {-NAc-glucosa- } \\
\text { minidase }\end{array}$ \\
\hline Fetal calf, & $250^{1}$ & 280 & 970 \\
$10 \%$ & $(170-320)$ & $(150-340)$ & $(800-1200)$ \\
Fetal calf, & 510 & 640 & 2700 \\
$30 \%$ & $(340-700)$ & $(400-850)$ & $(1700-3200)$ \\
Human AB & 800 & 1200 & 6500 \\
$\mathrm{Rh}^{+}, 30 \%$ & $(500-1110)$ & $(950-1800)$ & $(4700-7500)$ \\
\hline
\end{tabular}

${ }^{1}$ Each value represents the mean of four different experiments. The ranges of values obtained are given in parentheses. The cells were cultured for 7 days as described in the text.

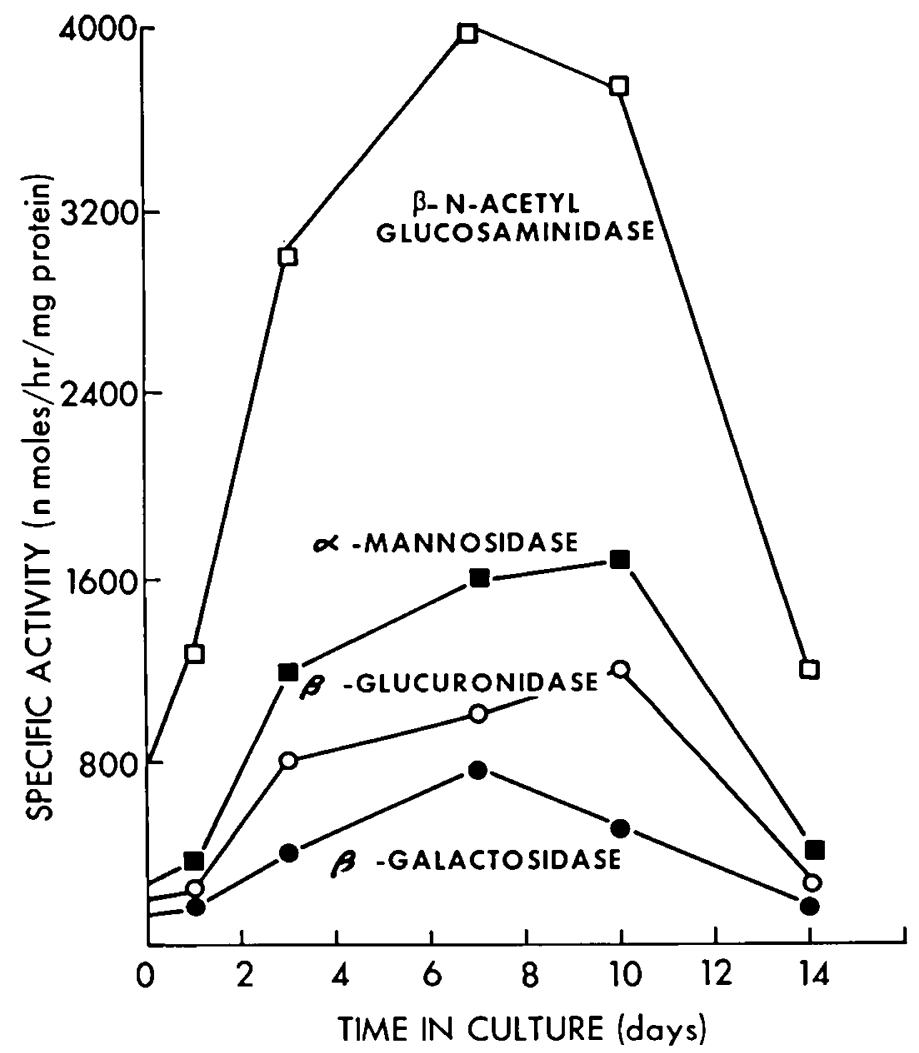

Fig. 1. The specific activities of four lysosomal hydrolases measured during the process of maturation of blood monocytes into mature macrophages.
Table 3. Lysosomal hydrolase activities in blood-derived macrophages and skin fibroblasts grown under same culture conditions

\begin{tabular}{lcc}
\hline & \multicolumn{2}{c}{ Activity, $\mathrm{nmol} / \mathrm{hr} / \mathrm{mg}$ protein } \\
\cline { 2 - 3 } \multicolumn{1}{c}{ Enzyme } & Macrophages & Fibroblasts \\
\hline$\beta$-Galactosidase & $800^{1}$ & 450 \\
& $(550-1200)$ & $(300-600)$ \\
$\beta$-Glucuronidase & 1200 & 550 \\
& $(850-1800)$ & $(400-750)$ \\
$\beta$-NAc-glucosaminidase & 6500 & 2300 \\
& $(4100-8200)$ & $(1900-3000)$ \\
\hline
\end{tabular}

${ }^{1}$ Each value represents the mean of 10 experiments. The ranges of values obtained are given in parentheses. The macrophages were cultured for 7 days in McCoy's medium supplemented with $30 \%$ human AB serum. Fibroblasts derived from skin biopsies were cultured in the same medium and assayed while in the $\log$ phase of growth.

est levels between days 7 and 10 of culture. This is in good correlation with the peak of $\beta \cdot N$-acetylglucosaminidase activity examined at the same time in parallel cultures of cells from the same individual (Fig. 2) and with the maximal activities of the four enzymes studied in separate experiments and displayed in Figure 1. Since both maximal or near maximal sulfate incorporation and enzyme activities are reached after 7 days of culture, the seventh day was chosen as the time at which kinetic studies were performed.

The relative rates of incorporation of ${ }^{35} \mathrm{SO}_{4}$ and of degradation of ${ }^{35} \mathrm{SO}_{4}$-MPS in macrophages and fibroblasts are shown in Figure 3 . When incubated continuously in radioactive sulfate, normal macrophages attain a steady state of labeling after only $5 \mathrm{hr}$ of incubation. After transfer to sulfate-free medium, about $60 \%$ of the labeled MPS is degraded in approximately the same $5-\mathrm{hr}$ period. By contrast, the kinetics of sulfate incorporation and of sulfated-MPS degradation are slower in fibroblasts, and steady states are not reached until about $24 \mathrm{hr}$. Moreover, the absolute incorporation of ${ }^{35} \mathrm{SO}_{4}$ on a per mg protein basis is about twice as great in blood-derived macrophages as in fibroblasts.

\section{MPS SYNTHESIS AND DEGRADATION IN BLOOD MONOCYTE- DERIVED MACROPHAGES FROM PATIENTS WITH HUNTER SYNDROME (MPS II)}

A total of six patients from three different families designated in Figure 4 as A, B, and C were investigated. Incorporation of sulfate into MPS during the 24-hr labeling period is about twice as great in MPS II cells as it is in normal cells. Conversely, only about $13 \%$ and $19 \%$ of labeled MPS are degraded by MPS II cells after 5 and $12 \mathrm{hr}$, respectively, as compared with 59\% and $67 \%$ degradation by normal cells. No differences in sulfated-MPS kinetics have been observed between the cells of patients with the MPS II who are only mildly affected and have no neurologic problems and the cells of those who are severely affected (37).

The MPS II macrophages that demonstrated impaired MPS degradation were grown in their own serum or in the serum of other patients with MPS II. These sera are known to be deficient in the lysosomal enzyme, iduronate sulfatase. As is shown in Figure 5, MPS II cells, when cultured in normal AB serum, show a significant correction of the metabolic defect. The ${ }^{35} \mathrm{SO}_{4}$ incorporation in $24 \mathrm{hr}$ is increased by only $25 \%$ rather than the 2 -fold observed in MPS II serum. In addition, the amount of degradation in $5 \mathrm{hr}$ is twice that observed when cells were grown in MPS II serum. A similar type of partial correction by normal serum has also been noted in cells obtained from one patient with MPS III.

\section{KINETICS OF MPS- ${ }^{35} \mathrm{SO}_{4}$ DEGRADATION IN OBLIGATE} HETEROZYGOTES FOR MPS II

The pattern of MPS- ${ }^{35} \mathrm{SO}_{4}$ degradation by macrophages of two obligate heterozygotes for MPS II, one studied twice, is shown in 


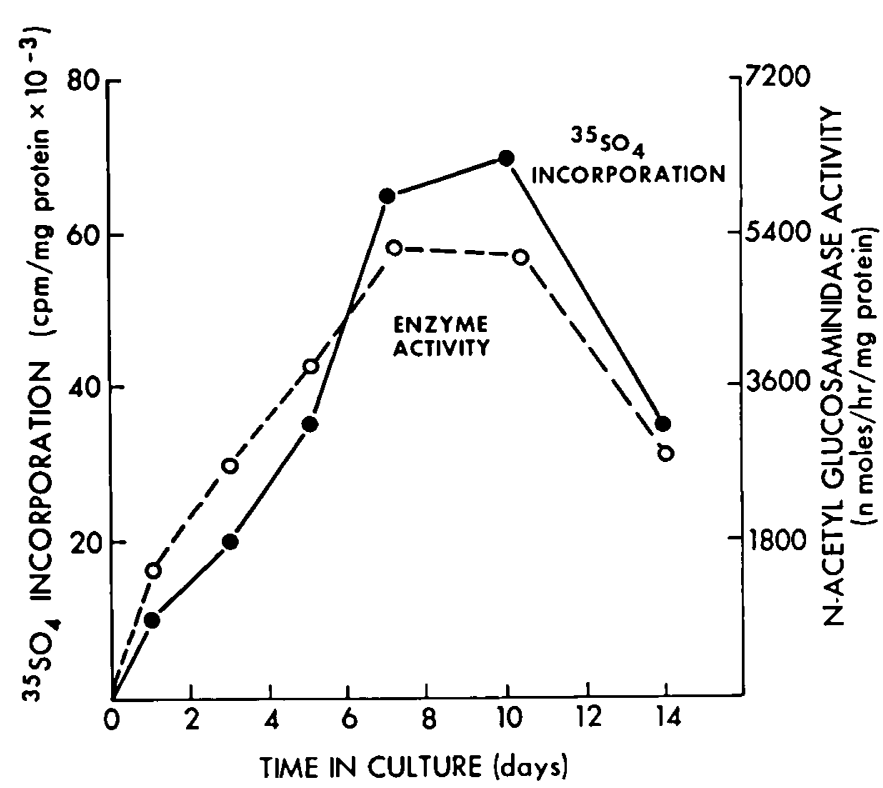

Fig. 2. Correlation between $\beta$ - $N$-acetylglucosaminidase activity and the rate of ${ }^{35} \mathrm{SO}_{4}$ incorporation into mucopolysaccharides during the process of maturation of blood monocytes to macrophages.

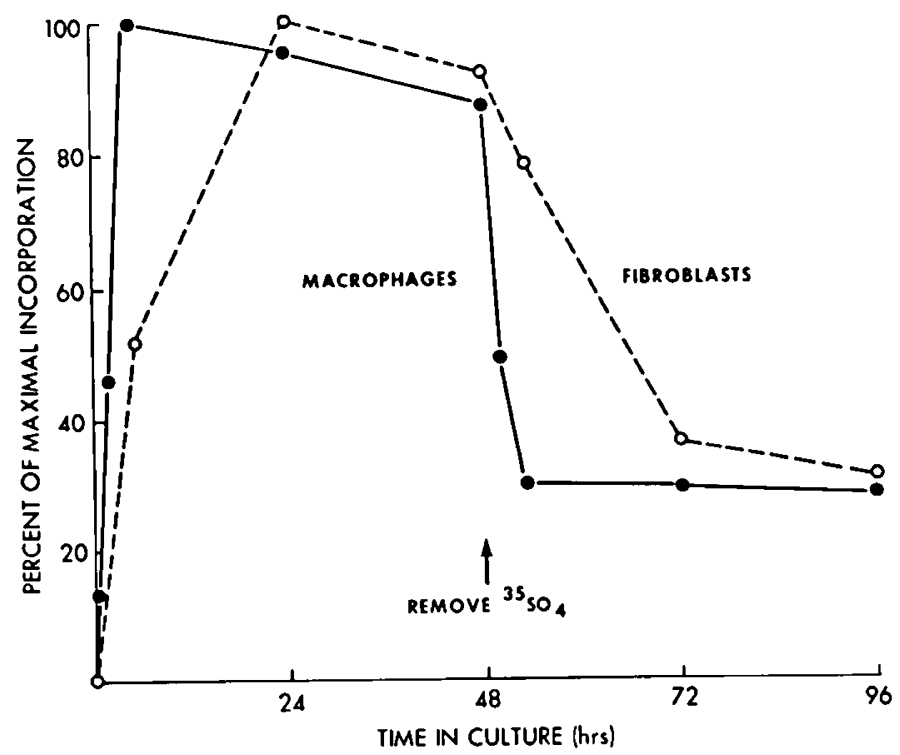

Fig. 3. Comparison of the relative rates of ${ }^{35} \mathrm{SO}_{4}$ incorporation and ${ }^{35} \mathrm{SO}_{4}$-MPS degradation in mature macrophages and cultured skin fibroblasts.

Figure 6. There is a higher incorporation of ${ }^{35} \mathrm{SO}_{4}$ after $24 \mathrm{hr}$ in the label and a higher than normal residual sulfated MPS content after 5 and $12 \mathrm{hr}$ in medium without label. Normal cells grown in the presence of MPS II serum demonstrated normal sulfate kinetics.

\section{DISCUSSION}

In this report we describe the use of an in vitro system for the study of lysosomal storage disorders in which we have employed human macrophages derived from the growth and differentiation of human peripheral blood monocytes. As has already been noted, such cells were chosen for study because they, being part of the reticuloendothelial system, are considered to be representative of the cells involved in the storage of undegraded substrates in several lysosomal storage disorders. In particular, we feel that macrophages may be more representative than are the skin fibro- blasts for the study of the storage and treatment aspects of this group of inherited diseases.

Many differences between macrophages and fibroblasts are known to exist (20). The two types of cells have different origins, with fibroblasts originating from mesenchymal cells and macrophages from hematopoietic stem cells. In addition, other criteria clearly distinguish "normal" macrophages from "normal" fibroblasts as well as from other types of cells (34). These include morphologic characteristics, enzyme activities (peroxidase and esterase), differences in specific surface antigens and receptors on the cell membrane, capacities for phagocytosis and pinocytosis, and survival and replicative capacity in cell culture systems.

Little information is available on normal macrophages from healthy individuals, and most of the published data is based on work with experimental animals. Our experiments provide additional biochemical data which illustrate the differences between human macrophages and fibroblasts. As is illustrated in Table 3, blood-derived macrophages have higher lysosomal activities than do fibroblasts, a difference possibly explainable by the active phagocytosis in which the macrophages are engaged. Furthermore, macrophages and fibroblasts differ with regard to the metabolism of mucopolysaccharides as represented by the kinetics of sulfate incorporation and of sulfated MPS degradation. The data illustrated in Figure 3 indicate that both the incorporation of $\mathrm{SO}_{4}$ into MPS and the degradation of sulfated MPS occur much more rapidly in macrophages than in fibroblasts. These differences may result from a combination of the active pinocytosis and secretion and of the high specific activities of lysosomal enzymes involved

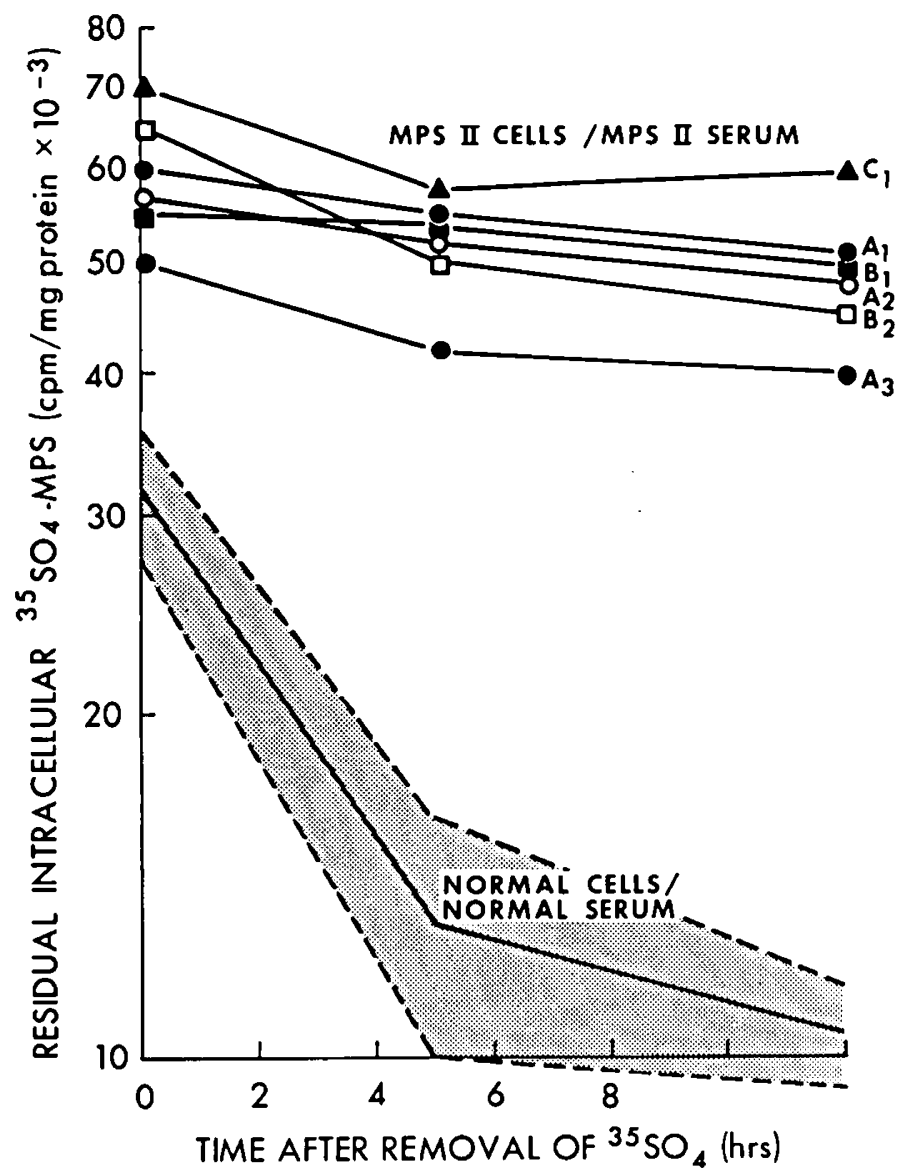

Fig. 4. The kinetics of ${ }^{35} \mathrm{SO}_{4}$-MPS degradation in macrophages from patients with MPS II and from normal individuals. A total of six patients from three different families designated as $\mathrm{A}, \mathrm{B}$, and $\mathrm{C}$ were investigated. The normal range (shaded) is represented by the mean $\pm 2 \mathrm{SD}$. The zero time at which the cells were placed in medium without ${ }^{35} \mathrm{SO}_{4}$ was after 24 $\mathrm{hr}$ of incubation in the radioactive precursor. 


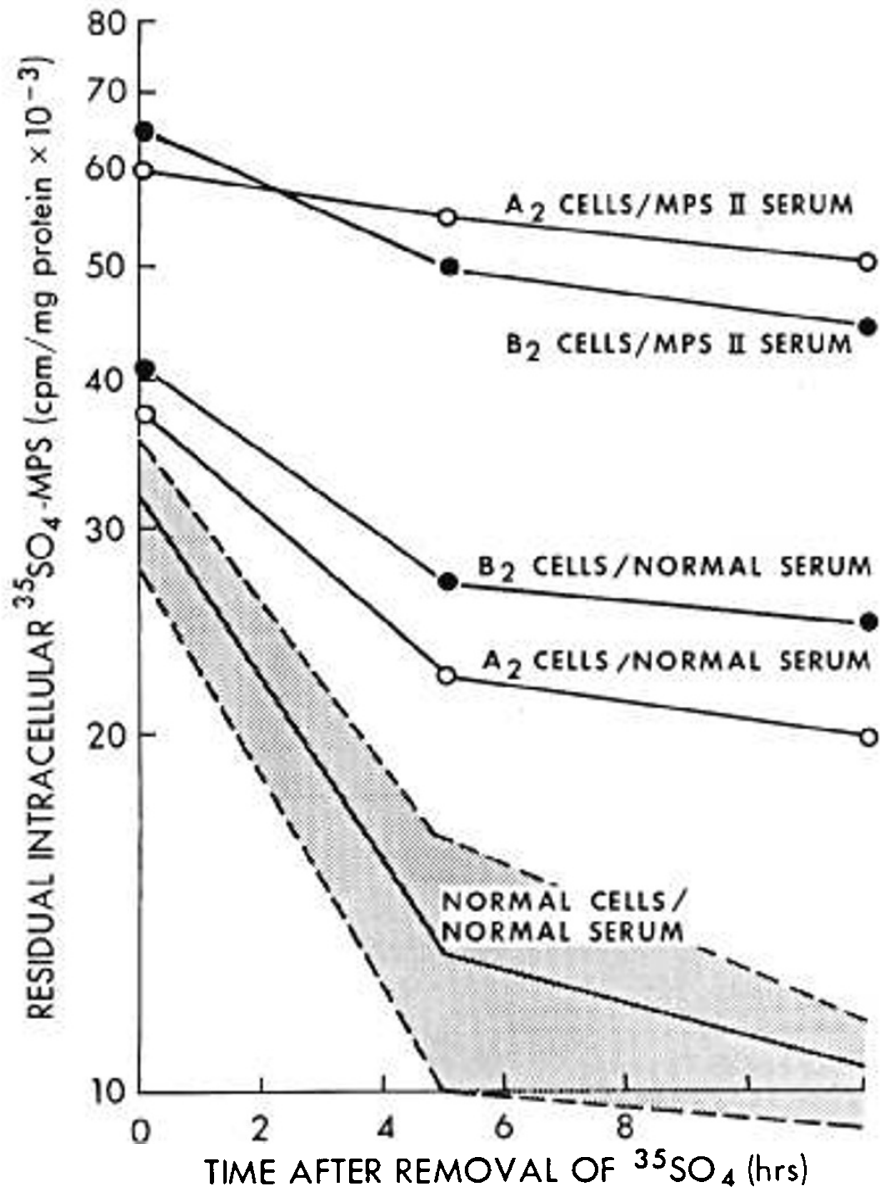

Fig. 5. The corrective effect of normal human serum on the impaired MPS degradation by MPS II macrophages grown in MPS II serum. The serum concentration in both instances was 30\% in McCoy's medium. The cells were incubated for $24 \mathrm{hr}$ in ${ }^{35} \mathrm{SO}_{4}$ prior to removal to fresh medium without precursor at time zero. The normal range (mean $\pm 2 \mathrm{SD}$ ) is indicated by the shaded area.

in mucopolysaccharide metabolism which characterizes the macrophage.

Since the peripheral blood-derived macrophage is an in vitro product of maturation of circulating monocytes, it is not necessarily identical to the more mature tissue macrophage. Our own unpublished studies indicate, for example, that the specific activities of several lysosomal hydrolases in human peritoneal macrophages obtained from patients with neoplastic disorders are significantly higher than in normal blood monocyte-derived macrophages, possibly because of the different milieu and stimuli to which these cells are exposed. Nonetheless, the process of maturation from blood monocytes to mature macrophages observed in vitro seems to be similar to that observed in vivo, and both in vitro and in vivo derived mature macrophages have similar characteristics in terms of plasma membrane constituents and physiology (including pinocytosis and phagocytosis), the nature of the vacuolar apparatus, the mode of intracellular digestion (16), and their functions in immune response $(7,31,36)$. Therefore, it seems safe to assume that the blood-derived macrophages are largely representative of tissue macrophages and will serve as good models for them.

The process of the in vitro transformation of blood monocytes to mature macrophages has been extensively studied by different investigators using mainly monocytes from animal sources $(2,16$, 33,35 ), and increases in lysosomal enzyme activities have been reported. Similar in vitro changes have also been described in cultured mouse peritoneal macrophages (16). Our present studies with macrophages derived from human blood monocytes also reveal that the specific activities of lysosomal enzymes in mature macrophages are significantly higher than those of the blood monocytes, with maximal activities being reached between days 7 and 10 of culture (Fig. 1).

One aspect of the in vitro maturation of human peripheral monocytes which has hitherto been unstudied is the turnover of mucopolysaccharides. In addition to the differences between macrophages and monocytes which have already been mentioned, our experiments demonstrate that the rate of sulfate incorporation into mucopolysaccharides is higher in the more mature blood-derived macrophages than in the monocytes and that the peak in rate of incorporation occurs at the time same time as the peak of lysosomal enzyme specific activity (Fig. 2). Furthermore, the studies attest to the feasibility of using the blood monocyte-derived macrophage for the study of mucopolysaccharide storage disorders. A defect of MPS degradation in macrophages from patients with MPS II is clearly illustrated in Figure 4. The abnormal turnover of ${ }^{35} \mathrm{SO}_{4}$ MPS can be reliably demonstrated within $5 \mathrm{hr}$ after the transfer of the labeled cells to sulfate-free medium. However, no differences in the kinetics of MPS turnover can be observed between cells of patients with the so-called "mild" and "severe" forms of MPS. In her earlier studies, using "white blood cell cultures" from patients with MPS I (Hurler syndrome) and MPS II, Danes also demonstrated an enhanced incorporation of ${ }^{35} \mathrm{SO}_{4}$ and $\left[{ }^{3} \mathrm{H}\right]$ acetate into MPS but did not directly study degradation (9).

The "corrective" effect of normal human serum which is known to possess iduronate sulfatase activity (19) on MPS II macrophages is clearly shown in our experiments (Fig. 5). This made it mandatory to carry out all kinetic experiments on MPS II cells in the presence of serum from MPS II rather than in normal serum.

The in vitro reconstitution of the catabolic pathways in different forms of mucopolysaccharidosis by adding "corrective" factors or purified enzymes to the medium has been demonstrated in the

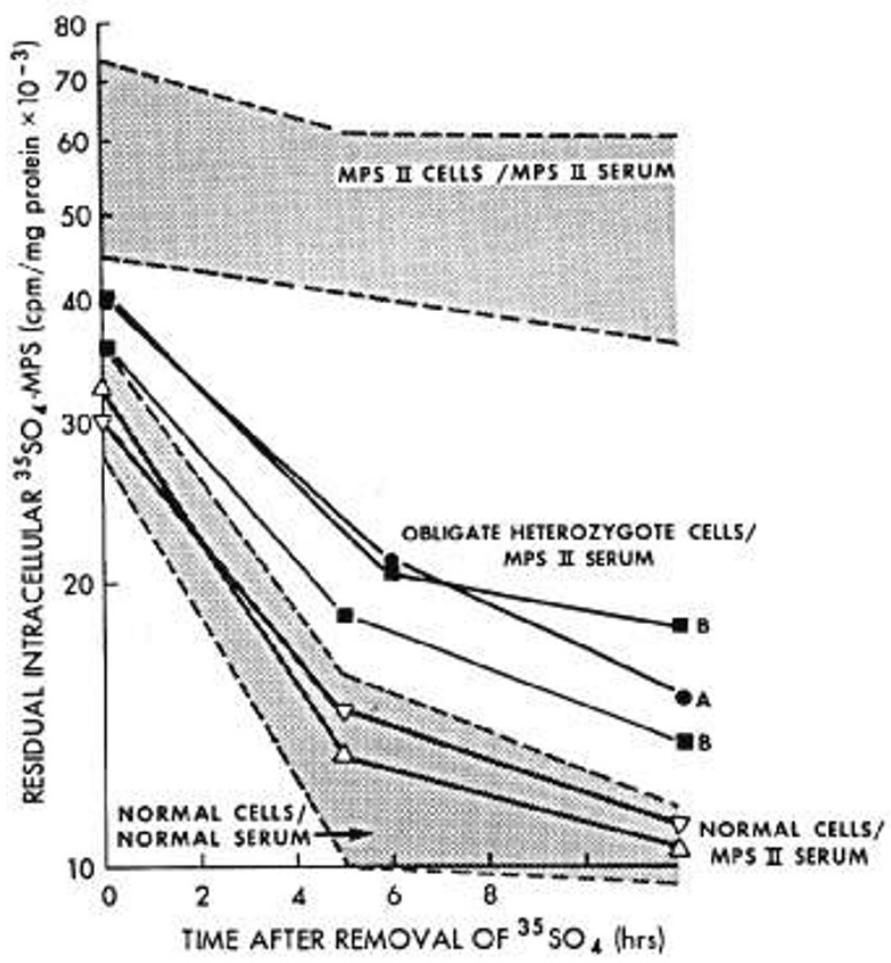

Fig. 6. Partial impairment of MPS degradation in macrophages of two obligate MPS II heterozygotes, a phenomenon demonstrated only when these cells were cultured in McCoy's medium with 30\% MPS II serum. The normal range (mean $\pm 2 \mathrm{SD}$ ) is indicated by the lower shaded area and the homozygous affected range (mean \pm 2 SD) by the upper shaded area. Normal cells cultured in MPS II serum do not show the impaired MPS degradation which characterizes the cells of obligate heterozygotes. 
fibroblast system by other investigators (25). From these experiments it was learned that only a small amount of the requisite enzyme need be added to the culture medium in order to show a large corrective effect (28). It was also found that the degree of the metabolic correction in vitro is correlated with the effectiveness of enzyme uptake by the cultured cells $(6,18,30)$. The high pinocytotic activity of the blood-derived macrophages in our system is probably the main reason for the high degree of responsiveness of cells from MPS II patients to the exogenously supplied soluble factor which is present in normal serum but is absent from the sera of MPS II patients.

Since two of the mothers of the children with MPS II were known to be obligate heterozygotes, each having had three affected sons, it was of interest to determine whether a partial impairment of mucopolysaccharide degradation could be demonstrated in their blood monocyte derived macrophages. At present, the detection of MPS II heterozygotes using fibroblasts is difficult primarily, it is thought, because of the phenomenon of cross correction between the two-cell populations of the heterozygote. In this situation, enzyme produced by normal cells is taken up by the abnormal cells. These cells are thereby "corrected" and, as a result, became capable of metabolizing MPS normally and have iduronate sulfatase activities within the normal range (21). Other investigators have claimed in vitro manipulations of tissue culture conditions (prolonged maintenance in culture or routine freezing) may induce preferential survival of mutant cells carrying the MPS II gene and, therefore, either impaired incorporation of ${ }^{35} \mathrm{SO}_{4}$ into MPS (3) or impaired degradation of ${ }^{35} \mathrm{SO}_{4}$-MPS (10) in skin fibroblasts of MPS II heterozygotes. Unfortunately, these manipulations do not produce an uniform response in obligate heterozygotes (3) and are not generally used. However, since bloodderived macrophages mature rapidly and have a rapid rate of MPS and possibly lysosomal enzyme turnover, we felt that growth in frequent changes of medium with noncorrecting MPS II serum might suppress the cross correction between normal and mutant cells for a long enough period of time to allow a metabolic defect, if present, to be demonstrated in heterozygotes. The preliminary investigation of cells from our obligate heterozygotes depicted in Figure 6 indicate that such a possibility for heterozygote identification may exist. If additional obligate heterozygotes present a similar pattern of MPS turnover, the blood-derived macrophage system may provide reliable method for detecting MPS II carriers. However, this approach to heterozygote detection is not presently suitable for clinical use, and the methods based on cloning of cultured fibroblasts (23) or analysis of hair bulbs (27) are currently preferable.

\section{REFERENCES AND NOTES}

1. Axline, S. G., and Cohn, Z. A.: In vitro induction of lysosomal enzymes by phagocytosis. J. Exp. Med., 131: 1239 (1970).

2. Bennett, W. E., and Cohn, Z. A.: The isolation and selected properties of blood monocytes. J. Exp. Med., 123: 145 (1966).

3. Booth, C. W., and Nadler, H. L.: Demonstration of the heterozygous state in Hunter's syndrome. Pediatrics, 53: 396 (1974).

4. Böyum, A.: Isolation of mononuclear cells and granulocytes from human blood. Scand. J. Clin. Lab. Invest., 21 (Suppl. 97): 77 (1968).

5. Brady, R. O., and King, F. M.: Gaucher's Disease. In: H. G. Hers and F. V. Hoof: Lysosomes and Storage Diseases, p. 381 (Academic Press, New York, 1973).

6. Brot, F. E., Glaser, J. H., Roozen, K. J., Sly, W. S., and Stahl, P. D.: In vitro correction of deficient human fibroblasts by $\beta$-glucuronidase from different human sources. Biochem. Biophys. Res. Commun., 57: 1 (1975).

7. Cohn, Z. A.: Recent studies on the physiology of cultivated macrophages. In: J. A. Bellanti and D. H. Dayton: The Phagocytic Cell in Host Resistance, p. 15 (Raven Press, New York, 1975).

8. Cohn, Z. A., and Benson, B.: The in vitro differentiation of mononuclear phagocytes. III. The reversibility of granule and hydrolytic enzyme formation and the turnover of granule constituents. J. Exp. Med., 122: 455 (1965)

9. Danes, B. S.: The use of white blood cell cultures in studying genetic metabolic diseases. Birth Defects: Original Article Series, Vol. 7, No. 1, p. 14l, 1971.

10. Donnelly, P. V., and DiFerrante, N.: Reliability of the Booth-Nadler technique for the detection of Hunter heterozygotes. Pediatrics, 56: 429 (1975).

11. Epstein, L. B., Cline, M. J., and Merigan, T. C.: Interaction of human macrophages and lymphocytes in the PHA stimulated production of interferon. J. Clin. Invest., 50: 744 (1971).
12. Fratantoni, J. C., Hall, C. W., and Neufeld, E. F.: The defect in Hurler's and Hunter's syndromes: Faulty degradation of mucopolysaccharide. Proc. Nat. Acad. Sci. U.S.A., 60: 699 (1968).

13. Fredrickson, D. S., and Sloan, H. R.: Glucosyl ceramide lipidoses: Gaucher's disease. In: J. B. Stanbury, J. B. Wyngaarden, and D. S. Fredrickson: The Metabolic Basis of Inherited Disease, Ed. 3, p. 730 (McGraw-Hill, New York, 1972).

14. Fredrickson, D. S., and Sloan, H. R.: Sphingomyelin lipidoses: Niemann-Pick disease. In: J. B. Stanbury, J. B. Wyngaarden, and D. S. Fredrickson: The Metabolic Basis of Inherited Disease, Ed. 3, p. 783 (McGraw-Hill, New York, 1972).

15. Glaser, J. H., and Sly, W.S.: $\beta$-Glucuronidase deficiency mucopolysaccharidosis: Methods for enzymatic diagnoses. J. Lab. Clin. Med., 82: 969 (1973).

16. Gordon, S., and Cohn, Z. A.: The macrophage. Int. Rev. Cytol., 36: 171 (1973).

17. Hirsh, J. G.: The phagocytic cell in host resistance: A perspective summation. In: J. A. Bellanti, and D. H. Dayton: The Phagocytic Cell in Host Resistance, p. 333 (Raven Press, New York, 1975).

18. Lagunoff, D., Nicol, S. M., and Pritzl, P.: Uptake of $\beta$-glucuronidase by deficient human fibroblasts. Lab. Invest., 29: 449 (1973).

19. Landing, B. H., Silverman, F. N., Craig, J. M., Jacoby, M. D., Lahey, M. E., and Chadwick, D. L.: Familial neurovisceral lipidosis. Amer. J. Dis. Child., I08: 503 (1964).

20. Leibovich, S. J., and Ross, R.: The macrophage and the fibroblast. In: R. van Furth: Mononuclear Phagocytes in Immunity, Infection and Pathology, Ed. 2 , p. 347 (Blackwell Scientific Publications, London, 1975).

21. Liebaers, I., and Neufeld, E. F.: Iduronate sulfatase activity in serum, lymphocytes and fibroblasts-simplified diagnosis of the Hunter's syndrome. Pediat. Res., 10: 733 (1975).

22. Lowry, O. H., Rosebrough, N. J., Farr, A. L., and Randall, R. J.: Protein measurement with the Folin phenol reagent. J. Biol. Chem., 193: 265 (1951).

23. Migeon, B. R., Sprenkle, J. A., Liebaers, I., Scott, J. F., and Neufeld, E. F.: Xlinked Hunter syndrome: The heterozygous phenotype in cell culture. Amer. J. Hum. Genet., 29: 448 (1977).

24. Nelson, D. S.: Immunobiology of the Macrophage (Academic Press, New York, 1976)

25. Neufeld, E. F., Lim, T. W., and Shapiro, L. J.: Inherited disorders of lysosomal metabolism. Ann. Rev, Biochem. 44: 357 (1975).

26. Nichols, B. A., and Bainton, D. F.: Ultrastructure and cytochemistry of mononuclear phagocytes. In: R. van Furth: Mononuclear Phagocytes in Immunity, Infection and Pathology, Ed. 2, p. 17 (Blackwell Scientific Publication, London, 1975).

27. Nwokoro, N., Liebaers, I., and Neufeld, E. F.: Iduronate sulfatase activity in hair roots of Hunter heterozygotes [Abstr.]. Amer. J. Hum. Genet., 29: 82A (1977).

28. O'Brien, J. S., Miller, A. L., Loverde, A. W., and Veath, M. L.: Sanfilippo disease type B: Enzyme replacement and metabolic correction in cultured fibroblasts. Science, 181: 753 (1973)

29. Raivio, K. O., and Seegmiller, J. E.: Genetic diseases of metabolism. Ann. Rev. Biochem., 41 : 543 (1972).

30. Shapiro, L. J., Hickman, S. G., Hall, C. W., and Neufeld, E. F.: Corrective and non-corrective forms of human $\alpha$-L-iduronidase [Abstr.]. Amer. J. Hum. Gen. 26: 79A (1974).

31. Steinman, R. M., and Cohn, Z. A.: The metabolism and physiology of the mononuclear phagocytes. In: B. W. Zweifach, L. G. Grant, and R. T. McCluskey: The Inflammatory Process, Ed. 2, p. 449 (Academic Press, New York, 1974).

32. Suzuki, K., Suzuki, K., and Chen, G. C.: Morphological, histochemical, and biochemical studies on a case of systemic late infantile lipidosis (generalized gangliosidosis). J. Neuropathol. Exp. Neurol., 27: 15 (1968).

33. Sutton, J. S., and Weiss, L.: Transformation of monocytes in tissue culture into macrophages, epithelioid cells and multinucleate giant cells: An electron microscope study. J. Cell Biol., 28: 303 (1966).

34. van Furth, R., Langevoort, H. L., and Schaberg, A.: Mononuclear phagocytes in human pathology-proposal for an approach to improved classification. In: $\mathbf{R}$ van Furth: Mononuclear Phagocytes in Immunity, Infection and Pathology, Ed. 2, p. 1 (Blackwell Scientific Publication, London, 1975)

35. Weiss, L. P., and Fawcett, D. W.: Cytochemical observations on chicken monocytes, macrophages and giant cells in tissue culture. J. Histochem. Cytochem. I: 47 (1953).

36. Weissmann, G., and Dukor, P.: The role of lysosomes in immune responses. Advan. Immunol., 12: 283 (1970).

37. Yatziv, S., Erickson, R. P., and Epstein, C. J.: Mild and severe Hunter syndrome within the same sibships. Clin. Genet., 11: 319 (1977).

38. The authors acknowledge the excellent technical assistance of Ms. Miriam Seelig Ms. Della Goldblatt, and Ms. Connie Reese.

39. Dr. Yatziv was the recipient of Fogarty International Fellowship (FO 5TW 2134), 1974-1976. His present address is Department of Pediatrics, the Hebrew University-Hadassah Medical Center, Jerusalem, Israel.

40. Dr. C. J. Epstein is an Investigator of the Howard Hughes Medical Institute.

41. This research was supported in part by grants from the National Institute of General Medical Science (GM-19527), the National Institute of Allergy and Infectious Disease (AI-12481), the National Cancer Institute (CA-14508), and the National Foundation-March of Dimes.

42. This work was presented in part at the 68th Annual Meeting of the American Society for Clinical Investigation, 1975 (Clin. Res., 26: 436A, 1976).

43. Requests for reprints should be addressed to: Dr. Charles J. Epstein, Department of Pediatrics, University of California, San Francisco, CA 94143 (USA).

44. Received for publication August 18, 1977.

45. Accepted for publication November $30,1977$. 